\title{
What Is Attention Deficit Disorder?
}

When the DSM-III was published in 1980, the diagnostic category of Attention Deficit Disorder (ADD) came into being. "Hyperactivity" and "hyperkinesis" had been the terms used during the 1960s and 1970s to refer to the childhood mental health disorder that we now call ADD and that is characterized by symptoms of inattention, impulsivity, and overactivity. Then as now these symptoms result in disruptions in school behavior, academic achievement, and relations with parents, teachers, peers, and siblings. The diagnostic constructs of hyperactivity and ADD describe the same children, even though they appear to focus on different core symptoms. There is not now and there never has been an accepted consensual definition of this diagnostic category, even though there are common factors among the various definitions that have been offered throughout the years. It is instructive to begin this chapter with examples of definitions that have been offered by influential investigators in the area.

First, although widely used and generally accepted as a label, the term "hyperactivity" does not provide an accurate description of the disorder to which it refers. Beginning with the early descriptions of the disorder, a variety of symptoms in addition to excessive motor activity have been noted. For example, Laufer, Denhoff, and Solomons ${ }^{1}$ listed symptoms of short attention span, poor concentration, unpredictable and explosive behavior, impulsivity, and low frustration tolerance, and they labeled the disorder "hyperkinetic-impulse disorder." The current focus is more on these symptoms of the disorder than on the excessive motor activity that gave the disorder the 
label by which it has been known for the past 20 years. One influential conceptualization is that ADD-H is a constitutional predisposition toward deficits in four major areas: (1) the investment, organization, and maintenance of attention and effort; (2) the inhibition of impulsive responding; (3) the modulation of arousal levels to meet situation demands; and (4) an unusually strong inclination to seek immediate reinforcement. ${ }^{2}$

After a careful review of the literature, Barkley ${ }^{3}$ offered the following definition of ADD:

\begin{abstract}
Hyperactivity, or attention deficit disorder, is a significant deficiency in age-appropriate attention, impulse control, and rulegoverned behavior (compliance, self-control, and problem solving) that arises by infancy or early childhood, is significantly passive in nature, and is not the direct result of general intellectual retardation, severe language delay or emotional disturbance, or gross sensory or motor impairment.
\end{abstract}

He advocates using standardized rating scales and questionnaires to measure the behaviors that are critical to his definition.

Similarly, Routh" states that hyperactivity "refers to a child's frequent failure to comply in an age-appropriate fashion with situational demands for restrained activity, sustained attention, resistance to distracting influences, and inhibition of impulsive response," and that the term is applied to children "whose behavior problems are severe enough to have come to professional attention, and whose difficulties are manifest in several situations over a considerable period of time." All of these conceptualizations are similar in their emphasis on deficits in attention and impulse control. Notably, an excessive activity level or "hyperactivity" is viewed as only one possible manifestation of the impulse control deficit, rather than a necessary component of these definitions. As do Barkley and Routh, many other definers also include the qualifications that symptoms be exhibited across situations and from a young age, both delimiters with the purpose of increasing the diagnostic homogeneity of the category. As discussed in Chapter 2, however, behavior varies widely across situations, and it is not a simple task to decide whether a child's problems occur across situations and whether failure to do that is a valid negative sign. Similarly, because of the unreliability of parental retrospective reports, it is very difficult, when faced with an 8-year-old child at first referral, to decide whether the child exhibited symptoms of ADD at age 3.

In an attempt to operationalize the definition of hyperactivity, many researchers have employed standardized parent and teacher rating scales, several of which are discussed in Chapter 2. A parent- 
teacher checklist that has been used to define hyperactivity in a number of studies is the Abbreviated Conners Rating Scale (ACRS), also known as the hyperkinesis index. ${ }^{5,6}$ This scale, shown in Figure $2-1$, requires the parent or teacher to rate 10 aspects of the target child's behavior. Each item on the ACRS is scored as applying (1) not at all, (2) just a little, (3) pretty much, or (4) very much. Weights from 0 to 3 are assigned to the categories (1) to (4), respectively, and a total score is calculated for the rated child. For normative samples, both the mean and the standard deviation (SD) are 5 for both parent and teacher ratings, and a cutoff score of 15, two SDs above the mean, has been widely used as an operational definition of hyperactivity and ADD. ${ }^{6,7}$ The validity of the cutoff as well as the scale have been questioned (see discussion in Chapter 2).

In contrast to the rationally derived ACRS there are several checklists on which item clusters labeled "hyperactivity" or "inattention" have been identified in factor analyses. The hyperactive and inattention factors on the full Conners Teacher Rating Scale (CTRS) are examples of these. ${ }^{6}$ Similarly, a factor labeled "impulsive-hyperactive" has been identified on the full Conners Parent Rating Scale, ${ }^{6}$ and factors variously labeled "hyperactivity," "immature," "immature-hyperactive," "attention problems-immaturity," and "motor excess" have emerged from factor analyses of different forms of the Child Behavior Checklist (CBCL) ${ }^{8,9}$ and the revised Behavior Problem Checklist. ${ }^{10}$ For all of these checklists, extensive normative data are available, and cutoff scores two SDs above normative means on these factors are usually utilized to define ADD.

Finally, two rating scales have been developed specifically to define ADD: (1) the ADD-H Comprehensive Teacher's Rating Scale (ACTeRS), ${ }^{11,12}$ shown in Figure 2-3; and (2) the Swanson, Nolan, and Pelham (SNAP) Rating Scale, ${ }^{13}$ shown in Figure 2-2. ACTeRS was described extensively in Chapter 2; SNAP will be described here.

The SNAP was developed by using the DSM-III criteria for ADD and the response format of the Conners scales to operationalize the actual DSM-III criteria for ADD. Thus the DSM-III defines ADD in terms of three of the four core symptoms listed on the SNAP-inattention, impuslivity, and hyperactivity-and the descriptive phrases listed under each symptom. The SNAP category of "peer interactions," although quite important (as will be shown below), is not part of the definition of ADD. A diagnosis of ADD-H requires the presence of each of the three core symptoms, while the diagnosis of ADD is made if the requirements for impulsivity and inattention are met but the requisite number of hyperactive symptoms have never been present. DSM-III guidelines regarding determination that the three core symptoms are present involve ascertaining that at least 
two of the descriptive criteria listed under hyperactivity on the SNAP and three each of the criteria listed under inattention and impulsivity be present. Interpreting a rater's check mark in the "pretty much" or "very much" columns as indicating symptom presence is a guideline that has been followed for diagnostic purposes in a number of recent research projects.

\section{ISSUES IN THE DEFINITION OF ADD}

The definitions and rating scales described above are among the most promising recent attempts to define the disorder now known as ADD. From the early description provided by Laufer and associates $^{1}$ to the most recent DSM version, they illustrate several noteworthy points regarding the definition of ADD. As discussed in Chapter 2, the diagnostic and definitional process in psychiatry is extremely complex, and none of these conceptualizations meets all of the criteria necessary to provide an adequate definition of ADD as a diagnostic category.

\section{Activity Level}

Although early researchers and clinicians focused on activity level as the central diagnostic feature of hyperactivity, ${ }^{14,15}$ the current consensus is that excessive motoric activity is not the most salient characteristic of the disorder. Attempts to define activity level objectively and to compare children referred for hyperactivity with nonhyperactive children often failed to reliably differentiate the two groups. ${ }^{16}$ For example, hyperactive children have been shown to fidget more than nonhyperactive children (normal, asthmatic, and behaviordisordered children) during task performance in a clinical setting, ${ }^{17}$ but observed measures of fidgeting in the classroom often failed to discriminate between hyperactive and nonhyperactive chidren. ${ }^{14,18}$

Even when between-group differences in activity level have been found, the utility of these differences for individual diagnosis has been limited. In one study hyperactive children exhibited significantly higher rates of both gross motor and minor motor movement in their regular classrooms. ${ }^{19}$ However, when cutpoints were used to classify group membership, the false negative and false positive rates were, respectively, 35 and 43 percent for minor motor movement and 42 and 20 percent for gross motor movement. The extensive overlap between groups in this and other studies, ${ }^{4}$ as well as the fact that $\mathrm{ADD}$-non-ADD differences in activity level vary with a variety of situational factors ${ }^{20}$ (as discussed in Chapter 2), casts 
doubt on the utility of excessive motor activity as a criterion for defining ADD and led to the current emphasis on inattention and impulsivity as the key symptoms of the disorder.

Even if an acceptably reliable and precise measure of activity level were devised, however, ${ }^{21}$ and reliable group differences were found, excessive activity level still might not be considered a necessary component or core symptom of the definition of hyperactivity. Excessive activity could result from a deficiency in attention or impulse control. Because a child would stick with each activity he or she began for a shorter period of time than a comparison child, the child with short attention span and low impulse control would be expected to move about the classroom more. Indeed, psychostimulant medication is presumed to effect a teacher-perceived decrease in activity because it lengthens a child's attention span and improves impulse control, resulting in more on-task behavior and fewer activity changes. ${ }^{22}$

\section{Inattention}

\section{Behavioral Measures of Attention}

As the name of the disorder suggests, deficits in attention are a pervasive and profound aspect of ADD. However, despite many studies and the consequent adoption of the term ADD, relatively little is known about the specific nature of the cognitive deficits in ADD children. ${ }^{2,23}$ For example, it is commonly accepted that hyperactive children have a shorter attention span and are more easily distracted than nonhyperactive children. This belief has derived primarily from teacher ratings and observation of classroom behavior and from analysis of hyperactive children's performance on laboratory tasks that measure sustained attention (vigilance). It is true that observations of classroom on-task behavior correlate highly with general ratings of disruption. ${ }^{24}$ However, teacher ratings more specific to inattention may not be valid indicators of actual attention deficits. Some studies have reported low to moderate correlations between teacher ratings of inattention and laboratory classroom performance. ${ }^{25}$ In contrast, when rating learning-disabled and normal children on the inattention factor of the CTRS, teachers in one study discriminated accurately between the groups but their ratings were not correlated with children's performance on four laboratory measures of selective attention, on which no group differences were found. ${ }^{26} \mathrm{~A}$ similar lack of correspondence between laboratory and classroom measures of attention has been evident in other studies. ${ }^{27,}{ }^{28}$ In addition, although "easily distracted" or "too distractible" is a symptom listed on all the major rating scales and in the DSM-III definition of ADD- 
$\mathrm{H}$, there is no evidence from laboratory studies that ADD children are more distractible than non-ADD children. $2,14,29,30$

In the search for the specific nature of ADD children's attentional problems, early studies of attention compared the performance of hyperactive and control children on a number of different laboratory tasks with results that have been subsequently widely replicated. ${ }^{2}{ }^{14}$ Hyperactive children showed poorest performance on tasks in which attention had to be maintained over a period of time and in which impulsive responding interfered with performance. Thus hyperactives had longer and more variable simple reaction times (RTs) following preparatory intervals, ${ }^{31}$ and made more errors of omission on a continuous performance test of vigilance. ${ }^{32}$ In a typical vigilance task, ADD children spend 15 to 30 minutes monitoring a series of targets, usually digits or letters, that appear briefly on a screen and then disappear. The child's task is to watch the screen and press a button each time a designated target (e.g., a " $b$ ") appears. In this situation, ADD children start out performing as accurately as comparison children, but their performance quickly deteriorates over time. They miss the targets (errors of omission) and press the button to incorrect targets (errors of commission) with increasing frequency as time goes by.

In contrast, ADD children performed as well as controls in choice RT tasks or self-paced serial RT tasks ${ }^{33}$ in which they do not have to maintain constant attention over time. In addition, ADD children performed more poorly than controls on the Matching Familiar Figures Test, which measures the child's ability to match a simple figure with a standard and in which careful visual scanning and impulse control are important performance-facilitating characteristics. ${ }^{34}$ Finally, Douglas and her colleagues found no evidence that ADD children were more distracted than controls when irrelevant stimuli were presented during task performance. ${ }^{32-34}$ Reviewing these and other studies, Douglas drew two conclusions that have been supported by continued research over the past decade: (1) ADD children have a constitutional inability to sustain attention and to inhibit responding in situations that require focused, directed, and organized effort; and (2) because of these deficits the children fail to apply sufficient, organized, and strategic effort to informationprocessing in task settings. ${ }^{29}$

In addition to sustained attention and distractibility, researchers have recently begun to study a third type of attention in ADD children-attention capacity, which is generally defined in terms of the child's ability to attend to or process a wide range of stimuli simultaneously. Studies of attentional capacity have shown that ADD children have performance deficits on these tasks; that is, they have increasing difficulty relative to control children attending to required 
stimuli as the number of stimuli and complexity of the task are increased. ${ }^{35,}{ }^{36}$ At the same time, it remains unclear whether this performance deficit reflects a basic processing deficit that is structural in nature or simply reflects difficulties in the appropriate application of task strategies caused by a sustained attention deficit. ${ }^{37-39}$

One of the most puzzling aspects of ADD children's attention deficits, as is the case with excessive activity level, is that they seem to be somewhat situationally specific. It is the rule rather than the exception among children seen by the author in a summer treatment program that children who exhibit difficulties on CPT tasks and in classroom on-task behavior are clearly able to maintain attention in high-interest situations, such as watching favorite movies or playing video games. Observations such as this one suggest that it is inappropriate to conclude that the problem of ADD children is due to the inability to sustain attention. At the least there must be some interaction between subject and task variables. Douglas ${ }^{2}$ has pointed out that it is very difficult to separate motivational from attentional factors when studying ADD children's task performance. This fact remains a major problem for researchers and theoreticians in the area.

\section{Physiological Measures of Attention and Arousal}

In addition to behavioral measures of attention such as reaction time and accuracy on information-processing tasks, physiological measures of attention and arousal have also been gathered during ADD children's task performance. Although the nature of the behavioral disturbances exhibited by ADD children led to early speculation that they suffered from a chronic state of overarousal, the attentional deficits observed on behavioral measures have led more recent theorists to argue that ADD children are in a chronic state of underarousal. ${ }^{20,}{ }^{23}$ When the research is carefully reviewed, however, results fail to consistently support either theory. For example, there is general agreement that ADD children as a group do not differ from non-ADD children on measures of basal autonomic arousal. ${ }^{40}$

Although there appears to be a consensus among reviewers that ADD children are underaroused or more specifically under-responsive in task situations, ${ }^{21,23,41}$ this conclusion is best viewed as tentative. ${ }^{37}$ In the past 5 years, techniques for using the EEG to measure cortical responsivity in task situations have been refined, and resulting research has provided more direct information regarding cortical attention/arousal than earlier autonomic studies. This research is still in its infancy, however, primarily because the relationships among direct measures of stimulus-evoked cortical potentials (EPs) and behavioral measures on information-processing tasks are not yet clearly understood, especially for children. ${ }^{42}$ Representative findings are those reported by Klorman and asociates ${ }^{43}$ and Callaway and as- 
sociates. ${ }^{44}$ Both sets of studies examined the late positive component of the EP (P300), which is thought to measure aspects of attentional processing in complex tasks. Klorman and associates found differences between ADD and control children that supported the underarousal hypothesis, while Callaway and associates' equally wellcontrolled study failed to support the notion that ADD children are cortically underaroused in task situations.

In summary, we can conclude that ADD children have an attention deficit, but that the precise nature of that deficit with regard to behavioral and physiological measures of cognition has not yet been identified. The reader may well be perplexed or disturbed that there is no clear understanding of the attention deficit in a disorder so named. One might even wonder why discuss the question of attention deficits if there is no clear answer regarding what they are. The purpose of this discussion was simply to give the practitioner a brief flavor of the research that has been conducted in this area and the equivocal nature of the results. None of this discussion has any implications for how one identifies or diagnoses an ADD child.

As Sleator discusses in Chapter 2, teacher ratings or other information on classroom behavior provide the best information for diagnosis. As she further indicates, many parents come to the pediatrician with the request that their child be tested to determine whether he or she has ADD. The present author can verify that many pediatricians subsequently refer the child to a psychologist with the same request-this is the most common referral question from physicians to the author's program at Florida State University. It is certainly worth emphasizing, as Sleator does, that there is no laboratory test, either physiological or behavioral, that can yield reliable and valid information regarding diagnosis of an attention deficit in an individual case. ${ }^{37,43}$ The one task that has shown most promise is the continuous performance (CPT) on vigilance task discussed above. However, even this task cannot be used with confidence to identify an attention deficit in a single case. There are not yet sufficient normative data available, nor has the relationship between performance on the CPT and the classroom behaviors of interest (on-task behavior, task completion) been sufficiently validated for use in individual cases. In spite of this, several firms are currently marketing to physicians a device (with a price tag of about $\$ 3000$ ) that administers a CPT task purported to be effective in diagnosing ADD in a 5-minute office evaluation. If the eager practitioner absolutely has to have some test to administer in the office that might provide useful information in conjunction with the other information Sleator recommends in Chapter 2, he or she will be well-advised (1) to purchase for less than $\$ 1000$ an Apple II computer, which can perform a variety of tasks; and (2) to copy a public-domain software version of a CPT 
task (most investigators listed in the reference section of this chapter have them). Rather than being stuck with an overpriced machine that is capable only of administering a CPT task and diagnostic guidelines of dubious validity, the practitioner would have a versatile computer that can be used for an increasing number of datagathering purposes (see discussion below).

\section{Impulsivity}

Laufer and associates" ${ }^{1}$ original name for hyperactivity, "hyperkinetic-impulse disorder," illustrates that impulsivity has long been presumed to be a core symptom of hyperactivity. Teachers and parents usually rate hyperactive children as more impulsive than nonhyperactive children, and observations of classroom behavior reveal that ADD children are different from comparison children on measures such as verbal interruptions. ${ }^{45,46}$ Standard laboratory measures of impulsivity such as the Matching Familiar Figures (MFF) test ${ }^{47}$ require children to inhibit responding and act planfully. Studies conducted with such measures have often revealed that hyperactive children respond more quickly and make more errors than normal comparison children. ${ }^{34}$ When hyperactive children in one study were compared with groups of asthmatic children and behavior-problem children, however, differences on the MFF were not apparent. ${ }^{17}$ In addition, it has been demonstrated that performance on the MFF does not correlate consistently or highly with teacher ratings, observations of impulsivity in the classroom, or other laboratory measures of impulsivity. ${ }^{48-50}$ The lack of a strong relationship among these measures casts doubt on the construct validity of impulsivity as it is currently operationalized. ${ }^{49}$

A separate factor describing impulsivity has often not emerged in factor analyses of teacher rating data, even though separate factors have been found for inattention and hyperactivity, the other core symptoms of ADD. Instead, items that describe impulsivity have loaded on factors variously labeled "hyperactivity," "conduct problems," "inattention," or "peer problems." $11,52,89$ For example, a factor analysis of the SNAP Rating Scale yielded three factors that appeared to tap hyperactivity, inattention, and peer problems. ${ }^{52}$ The DSM-III impulsivity items split between the inattention and peer problem factors, indicating that they did not "hang together" as a separate construct. This makes intuitive sense when the items are examined (see the SNAP in Figure 2-2). For example, "has difficulty organizing work" appears and is more closely related to attentional functioning than it is to the construct of impulsivity. Similarly, "has difficulty waiting for turn in games or group situations" is more 
highly related to other indices of peer relations than it is to performance on the MFF test. In general, the existence and utility of the construct of impulsivity as a symptom of hyperactivity independent of inattention, excessive activity, and conduct problems have not been demonstrated. ${ }^{49}$ Efforts to improve the operationalization of impulsivity have involved the development of a teacher checklist designed specifically to measure impulsivity ${ }^{53}$ and adaptation of the MFF to yield a more reliable measure. ${ }^{54}$

These refinements are of more interest to researchers than practitioners, however. There are no measures of impulsivity other than teacher ratings that are capable of providing clinically useful information for pediatricians. As with measures of inattention, there are firms that market expensive devices purported to measure impulsivity in a quick office visit, but these are insufficiently validated to be of clinical utility at present.

\section{ADD-H as a Syndrome}

For many years it was assumed that ADD-H was a homogeneous syndrome comprised of the core symptoms described above. Children diagnosed as hyperactive were presumed to exhibit all of the core symptoms, and children with a high level of one core symptom were assumed to exhibit high levels of the other core symptoms. Although no definitional systems actually required that all symptoms be present, a procedure followed also in DSM-III, most professionals nonetheless believed that $\mathrm{ADD}-\mathrm{H}$ was a unitary syndrome. In contrast to the widespread belief in a syndrome, a number of studies have addressed this question, and with few exceptions have failed to provide supportive evidence. Limited evidence in support of a syndrome comes from the factor analytic studies of clinic or normal populations which have yielded factors labeled hyperactivity. ${ }^{55} \mathrm{Al}$ though often correlated with factors reflecting conduct disorder, ${ }^{7}$ the hyperactivity factors have nonetheless been distinct from conduct factors, and the failure to find hyperactivity factors in some studies ${ }^{56}$ may have resulted from limitations in the rated sample or in the included items. ${ }^{51}$

The fact that a hyperactivity factor is often found, however, is not sufficient evidence that the disorder is a unitary syndrome. Factor labels do not always accurately reflect the items loading on a factor. In the Lahey and associates ${ }^{51}$ study, for example, a number of items that described impulsivity loaded on the conduct factor rather than the hyperactivity factor. If hyperactivity is a syndrome, all of the symptoms attributed to the disorder, especially the core symptoms, should load on one factor. Very little of this type of support 
for the syndrome is evident. In one early study, 67 variables thought to be related to hyperactivity were entered in a factor analysis with a sample of hyperactive children. ${ }^{57}$ Ten factors emerged from the analysis. No factor could be labeled hyperactivity, nor were there factors present reflecting each core symptom. Instead, factors were related to the data sources and included neurological examination factors, psychological test factors, psychiatric evaluation factors, and so on.

Similarly, Langhorne and associates ${ }^{58}$ performed a factor analysis of measures from four sources (raters of children's clinic charts, psychiatrist's diagnosis, teacher ratings, and parent ratings) of the following symptoms of hyperactivity: inattention and difficulty concentrating, hyperactivity and fidgetiness, lack of judgment, impulsivity and excitability, diagnosis, and problem duration. As in Werry's study, the resulting factors reflected source-related factors (a chart rating and two teacher rating factors) rather than child-related factors. Of particular interest is the observation that chart ratings and teacher ratings of the same symptoms loaded on different factors.

These and other factor analytic studies ${ }^{59}$ thus did not yield evidence for a syndrome of hyperactivity. Together with the equivocal results from the group comparisons of activity level, inattention, and impulsivity, this finding shows that a homogeneous syndrome of hyperactivity, as previously described, has not been identified. ${ }^{60} \mathrm{Un}$ fortunately, corresponding research on the SNAP Rating Scale has revealed similarly low interrater agreement and a lack of construct validity, suggesting that the DSM-III definition of attention deficit disorder has not solved the problems in heterogeneity of hyperactivity. ${ }^{52,61}$ The category of hyperactivity is a heterogeneous one that includes children with quite different symptom patterns and prognoses, and in all likelihood different etiologic and mediating variables. Much of the recent research in the field has begun to focus on the subdivision of hyperactivity with the expectation that subcategories that are homogeneous at least with respect to symptomatology can be identified.

\section{Summary}

The problems of definition outlined in this chapter should sensitize the practitioner to the complexities involved in defining the disorder. Given the current state of knowledge in child psychopathology, the primary purpose of definition and diagnosis is to provide groups of individuals whose etiological, mediating, and prognostic similarities and differences can be studied. This discussion should alert researchers to the relative heterogeneity of the disorder, the debates 
regarding the validity for its defining criteria, and necessary directions for future research on definition.

In contrast, the primary concern for the practitioner should not be to provide a refined diagnosis acceptable for research purposes but instead to provide assessment of the child's presenting problems. As Chapters 2 and 5 discuss, the identification of the child's specific problem behaviors in the context of a functional analysis should be the major focus of assessment in clinical settings. The output of such an assessment provides the basis for a treatment plan. In the current state of the art in nomenclature in child psychopathology, no useful information is conveyed from a diagnosis alone. ${ }^{62}$ If a diagnosis is required-for educational placement, for example, or other purposes - the diagnostic scheme for ADD in DSM-III should be used, with the SNAP Rating Scale or the other rating scales described in Chapter 2 used by both parents and teachers to provide information for diagnosis. If norms for laboratory measures and classroom observational measures of attention and impulsivity are developed, then attempts should be made to tap these sources in clinical settings. As yet, none are available.

\section{ASSOCIATED PROBLEMS}

A number of behavioral correlates of hyperactivity are not included in formal diagnosis or definition of the disorder. Recent research, however, has suggeseted that some of these correlates play an important role in hyperactivity and should be considered in evaluation and treatment.

\section{Aggression and Hyperactivity}

Although children with predominantly hyperactive symptoms have long been differentiated in clinical diagnosis from those with predominately aggressive symptoms, some researchers have recently argued that ADD and conduct disorder are two subcategories of the same disorder. ${ }^{56}$ For example, when separate hyperactivity and conduct disorder factors emerge in factor analysis, as on the CTRS, they are highly correlated $(r=.7) .{ }^{5,7}$ Such high correlations, however, do not necessarily mean that the two diagnostic categories cannot be differentiated. ADD and conduct disorders can be operationally defined, as in DSM-III, in such a way that reliable differential diagnosis can be made from a structured interview with the child's parent. ${ }^{63}$ 
Because conduct disorder and hyperactivity rating scale factors share common variance, the relationship between aggression-the primary symptom of conduct disorder-and ADD has been a subject of considerable interest among researchers. Parents rate 59 percent of their ADD children as aggressive, ${ }^{15}$ teachers reported that 24 percent of one sample of ADD children exhibited extreme rates of aggression, ${ }^{64}$ and peers nominate 40 to 50 percent of ADD chldren as aggressive. ${ }^{65}$ Studies have thus addressed whether ADD children can be subdivided on a dichotomy defined by the presence of aggressive symptomatology. In the first of these studies, ${ }^{66}$ raters examined the clinic charts of 135 hyperactive boys and coded variables reflecting primary symptoms and secondary symptoms. Primary symptoms included judgment deficits (impulsivity), hyperactivity, inattention, uncoordination, and fidgetiness. Secondary symptoms, presented to result from the child's flawed interactions with his or her environment, included control deficits (e.g., delinquent acts, evasion of the rules), negative affect (e.g., irritability), and aggressive interpersonal behavior. Factor analysis of these ratings revealed two factors: aggression, on which the three secondary symptoms loaded; and hyperactivity, on which the core symtpoms (hyperactivity, impulsivity, and inattention) loaded. In order to explore the meaningfulness of the two factors, factor scores were computed for each child, and the relationship between these scores (correlated with $r=.27$ ) and other variables were examined. Teacher ratings of a variety of acting-out problems (e.g., destructive, defiant, quarrelsome, temper outbursts) correlated significantly with the aggression factor, while teacher ratings on items more descriptive of a typical ADD child (e.g., restless/overactive, inattentive, disturbs other children) correlated with the hyperactivity factor. SES was correlated with the aggression factor, as were maternal hostility and absence of maternal control. Neurological signs were negatively correlated with the aggression factor, and diagnosis of hyperkinesis and response to medication were correlated with the hyperactive factor.

Thus a single-source factor analysis performed on ratings of ADD symptoms yielded two distinct dimensions of the disorder, hyperactivity and aggression, demonstrating that aggressive behavior is an important dimension in ADD children. These results have been replicated using the same measures with a sample of consecutive referrals to a clinic, ${ }^{67}$ and they have been replicated with a different sample of hyperactive children using teacher ratings rather than chart raters as the source of information. ${ }^{68}$

Scores on these aggression and hyperactivity factors have been correlated with a number of variables in addition to the ones previously noted, and it is clear that discriminating among hyperactive 
children on the basis of aggressive symptomatology provides critical information regarding etiologic, treatment, and prognostic variables. ${ }^{69-71}$

For example, Milich and Landau ${ }^{72}$ have conducted a series of studies in which they examined the peer relationships of "pure" ADD boys (those without aggressive symptomatology), "pure" aggressive boys (those without ADD), and boys with both sets of symptoms. They have found patterns of results suggesting that boys with both ADD and aggression have the most seriously disturbed peer relations. Similarly, Milich and Loney ${ }^{70}$ reviewed many studies of long-term prognosis in children with behavior problems, and they concluded that among the ADD group, children with aggressive symptoms have by far the worst prognosis (see the discussion in Chapter 6).

In an attempt to provide a clinically useful and practical procedure for gathering information on both ADD and aggressive symptoms, Loney and Milich developed a rating scale by taking items from the CTRS that correlated highly with the chart ratings discussed above. This resulting scale, the IOWA Conners Teaching Rating Scale, ${ }^{69}$ has 10 items, 5 of which tap ADD and 5 of which tap aggressive behaviors. The $5 \mathrm{ADD}$ items are fidgeting; hums and makes other odd noises; excitable, impulsive; inattentive, easily distracted; and fails to finish things started (short attention span). The 5 aggression items are quarrelsome; acts "smart"; temper outbursts (explosive and unpredictable behavior); defiant; and uncooperative. The response format and scoring procedures for the scale are the same as those for the ATRS shown in Figure 2-1. Norms for the IOWA Conners scale have recently been reported. ${ }^{73}$

The utility of the IOWA Conners scale was demonstrated in a recent study in which ADD boys were followed for 3 years, from early through later elementary school, to determine whether the children's peer relations improved over time. ${ }^{74}$ All the ADD boys had seriously disturbed peer relations as determined by peer ratings at initial contact. Three-year follow-up results revealed that ADD boys with scores below a cutoff point on the IOWA Conners Aggression scale had normal peer ratings at follow-up, while those with scores above the IOWA Aggression cutoff continued to have seriously disturbed peer relations. In fact as a group the boys with high Aggression scores had shown no improvement at all. Such information is useful to a practitioner, as it identifies children at greatest risk for worsening of symptoms and in greatest need of intensive treatment.

The discussion of the relationship between ADD and aggression has been brief, but it should be clear that information on an ADD 
child's concurrent level of aggression is critical and should be gathered routinely (as described in Chapters 2 and 5). Unfortunately, this information was not gathered in most early studies of ADD-H and therefore cannot be discussed with respect to some of the most crucial data (e.g., those from the few prospective ADD follow-up studies described in Chapter 6). Results from those early studies must be evaluated with this omission in mind.

\section{Peer Relationships}

Only recently have peer relationships in hyperactive children been studied. In child psychopathology, the domain of peer relationships is thought to be important because several studies have shown that the best childhood predictor of adult maladjustment is the number of negative nominations received on classroom peer rating measures. ${ }^{75-77}$ Because peer relationships are considered one of the most critical facets of the childhood socialization process, ${ }^{78}$ disturbances in peer relationships may thus be both important predictors and important mediators of outcome in hyperactive children. ${ }^{79}$

Data regarding peer relationships in hyperactive children have been drawn from several different sources. Teachers have rated hyperactive children as having more disturbed peer interactions than comparison children. ${ }^{80}$ Teacher ratings of peer problems in one study discriminated between hyperactive and comparison children as well as did teacher ratings on the core symptoms of the disorder. ${ }^{65}$ Peer evaluations, the most important measure of peer relations, have also been examined. ${ }^{81}$

Consider one study in which the author gathered sociometric information in the form of positive and negative peer nominations of ADD children. The research team obtained permission to go into the regular classrooms of referred ADD children. Without letting the children know the purpose of the interviews, each child in a class met individually with an adult and was asked to name three classmates whom he or she liked a lot and three classmates whom he or she did not like at all. In the sample of 49 ADD children (consecutive referrals for treatment studies), 47 children received a higher number of negative nominations (named as disliked) than did their average classmates. ${ }^{65}$ Twelve percent of the sample obtained negative nominations between their class mean and one SD above it, 22 percent obtained negative nominations between 1 and 2 SDs above class means, and 60 percent obtained negative nominations greater than 2 SDs above their class means. Seventy-four percent of these same children failed to receive as many positive nominations (named as 
liked) as their average classmates, including 72 percent who received no positive nominations.

These peer reports have been corroborated by data from direct observations of ADD children in school settings, ${ }^{82}$ as well as in playgroups with nonhyperactive unfamiliar peers. ${ }^{65}$ In the latter study, large significant differences were apparent in both structured and unstructured play situations. Compared to controls, ADD children exhibited three times as much negative nonverbal behavior (e.g., fighting), five times as much high-rate behavior (e.g., yelling, running around), twice as much verbal initiation, and eight times as many negative verbalizations. After only two 90-minute play periods, the peers who interacted with these ADD children rated them so negatively that the ADD children could be distinguished from controls almost perfectly on the basis of the peer ratings alone.

Similar results were obtained in an extensive sociometric study. ${ }^{65}$ Using the Pupil Evaluation Inventory (PEI), ${ }^{83}$ a group of 52 boys and 12 girls who fit teacher rating criteria for ADD were compared to 251 nonhyperactive boys and 272 nonhyperactive girls in two large elementary schools. The PEI consists of 35 descriptive statements on which all children in a classroom nominate classmates to whom each statement applies. Factors named aggression, withdrawal, and likeability have been identified. ${ }^{83}$ These results revealed that ADD children were significantly different from comparison children on each of these three factors. The results are presented for individual PEI items in Table 3-1, which reveals that ADD children were consistently rated as different from comparison children on items that tapped aggression, interruptions, disruption, teasing, and annoying behaviors. Their peers also perceived ADD children as having more difficulty sitting still and as doing more things that bothered the teacher, but it is noteworthy that ADD children were rated as most different from comparison children on items that referred to peer relationships.

In addition to the ADD-H-normal comparison in the Pelham and Bender study, the relationship between the aggressive/hyperactive dichotomy discussed earlier and these peer ratings was examined. Using teacher ratings, four groups of ADD-H boys were formed by crossing high and low scores on aggression and hyperactivity factors, ${ }^{68}$ and the PEI data were reanalyzed using these groupings. Results revealed that high aggressive children were nominated most frequently by peers on items related to aggression. In contrast, both high aggressive and high hyperactive boys were nominated frequently on items such as "those who bother other people when they are trying to work" and "those who are chosen last to join in group activities." Thus, although high levels of both hyperactivity and aggression were related to negative nominations, the factors were re- 
lated to different types of negative nominations. Consistent with the discussion above, children with high levels on both ADD and aggressive symptoms had the most extreme peer ratings.

It is clear that hyperactive children have very serious disturbances in peer relationships, and it is likely that these disturbances play an important mediating role in both the current severity and the long-term outcome of the disorder. Information in this domain should be routinely gathered both in research settings (especially in studies that examine prognosis) and in clinical practice. In the latter case, such information should alert clinicians to the need for a treatment component that focuses on problems in peer relationships.

As discussed in Chapter 5, assessment and treatment of problems in peer relationships is very difficult and must involve intensive data gathering and treatment in the school setting. The pediatrician who refers an $\mathrm{ADD}$ child to a psychiatrist or psychologist for treatment should be wary of any mental health professional who purports to be able to assess peer relationships without gathering sociometric data from the referred child's classmates and without treating the peer interactions in the school setting. The correlation between teacher assessment of peer problems and peer assessment of those same problems is low, necessitating information gathering from peers, and treatment that is office-based is worthless.

\section{Learning Problems}

Although it is commonly noted that 25 to 50 percent of ADD children have serious problems in learning ${ }^{84}$ the difficulties of defining learning disabilities are as great as those involved in defining hyperactivity, ${ }^{85}$ making investigation of the relationship between the disorders especially problematic. One recent study showed that the prevalence of learning disabilities ranged from 4 to 53 percent in a sample of hyperactive children, depending on the criteria used to define the two disorders. More stringent criteria were associated with the lower prevalence rate. ${ }^{86}$ The commonly cited rates of 25 to 50 percent should thus probably be interpreted as the upper limits of the prevalence of learning disability in an ADD sample.

Obtaining information on learning in ADD children is important for both research and clinical purposes. In research, ADD children with and without associated learning problems should be examined separately in order to insure that findings regarding cognitive and physiological correlates are a function of ADD per se rather than associated learning disabilities. Unfortunately, with few exceptions ${ }^{87,88}$ this separation has not been made in most studies of cognitive deficit in ADD, and interpretation of these studies' results is conse- 
TABLE 3-1. MEANS AND STANDARD DEVIATIONS FOR THE HYPERACTIVE AND NONHYPERACTIVE SAMPLES ON ITEMS FROM THE PUPIL EVALUATION AND RESULTS FROM 2 (GROUP) $\times 2$ (SEX) ANOVAS ON EACH ITEM ${ }^{2}$

\begin{tabular}{|c|c|c|c|c|c|c|c|c|c|c|c|}
\hline \multirow{2}{*}{\multicolumn{2}{|c|}{ Item }} & \multicolumn{4}{|c|}{ Boys ${ }^{b}$} & \multicolumn{4}{|c|}{ Girls ${ }^{c}$} & \multirow[b]{2}{*}{ Group Effect ${ }^{\alpha}$} & \multirow{2}{*}{$\begin{array}{l}\text { Group } \times \operatorname{Sex}^{0} \\
\text { Interaction }\end{array}$} \\
\hline & & \multicolumn{2}{|c|}{ Hyperactive } & \multicolumn{2}{|c|}{ Nonhyperactive } & \multicolumn{2}{|c|}{ Hyperactive } & \multicolumn{2}{|c|}{ Nonhyperactive } & & \\
\hline $1 .^{\circ}$ & Those who are tall & 25.6 & $(31.9)$ & 21.3 & $(16.8)$ & 12.9 & (16.3) & 20.6 & (26.9) & $F<1.0$ & $F=1.8$ \\
\hline 2. & Those who help others & 9.4 & (6.3) & 25.0 & $(19.6)$ & 18.2 & $(13.8)$ & 37.2 & $(24.0)$ & $F=24.5^{\star \star \star \star \star *}$ & $F<1.0$ \\
\hline 3. & Those who can't sit still & 58.2 & $(18.0)$ & 24.8 & $(21.4)$ & 39.3 & $(28.8)$ & 15.2 & (18.5) & $F=100.2^{\star \star \star \star \star \star}$ & $F=1.6$ \\
\hline 4. & $\begin{array}{l}\text { Those who try to get other people } \\
\text { into trouble }\end{array}$ & 50.7 & (23.9) & 17.2 & $(18.6)$ & 30.1 & $(18.9)$ & 10.1 & $(14.4)$ & $F=127.0^{* * * * *}$ & $F=4.4^{*}$ \\
\hline $5 .^{\circ}$ & $\begin{array}{l}\text { Those who are too shy to make } \\
\text { friends easily }\end{array}$ & 10.8 & (10.3) & 8.5 & $(10.0)$ & 8.5 & (9.3) & 13.6 & $(14.6)$ & $F<1.0$ & $F=3.3$ \\
\hline $6 .^{\circ}$ & $\begin{array}{l}\text { Those whose feelings are too easily } \\
\text { hurt }\end{array}$ & 13.5 & $(13.6)$ & 9.8 & $(10.9)$ & 18.7 & $(16.0)$ & 15.4 & $(14.0)$ & $F=4.3^{*}$ & $F<1.0$ \\
\hline 7. & $\begin{array}{l}\text { Those who act stuck-up and think } \\
\text { they are better than everyone else }\end{array}$ & 38.2 & (18.3) & 16.1 & $(14.8)$ & 23.3 & $(15.2)$ & 13.0 & $(12.7)$ & $F=77.1^{* \cdots * * *}$ & $F=5.1^{*}$ \\
\hline 8. & $\begin{array}{l}\text { Those who play the clown and get } \\
\text { others to laugh }\end{array}$ & 40.2 & $(18.5)$ & 19.3 & (18.9) & 16.7 & $(15.2)$ & 8.1 & $(10.6)$ & $F=56.3^{* * * * * *}$ & $F=4.6^{*}$ \\
\hline $9 .^{\bullet}$ & Those who start a fight over nothing & 47.8 & $(22.5)$ & 19.1 & $(19.2)$ & 24.9 & $(18.2)$ & 9.0 & $(12.2)$ & $F=133.0^{\star \star \star \star \star \star}$ & $F=5.4^{*}$ \\
\hline 10. & $\begin{array}{l}\text { Those who never seem to be having } \\
\text { a good time }\end{array}$ & 17.4 & $(12.4)$ & 7.9 & $(8.6)$ & 16.3 & $(15.2)$ & 9.4 & $(10.5)$ & $F=33.3^{\star \star \star \star \star \star}$ & $F<1.0$ \\
\hline 11. & $\begin{array}{l}\text { Those who are upset when called on } \\
\text { to answer questions in class }\end{array}$ & 25.5 & $(16.2)$ & 9.5 & $(9.7)$ & 15.9 & (13.3) & 7.6 & $(9.8)$ & $F=76.7^{* \star * \star *}$ & $F=4.1^{*}$ \\
\hline 12. & $\begin{array}{l}\text { Those who tell other children what to } \\
\text { do }\end{array}$ & 41.2 & $(22.9)$ & 15.7 & $(14.0)$ & 21.7 & $(15.4)$ & 14.7 & $(13.1)$ & $F=88.2^{\star \star \hbar \hbar \hbar \star}$ & $F=12.1^{* * *}$ \\
\hline 13. & $\begin{array}{l}\text { Those who are usually chosen last to } \\
\text { join in group activities }\end{array}$ & 27.0 & $(16.5)$ & 13.2 & $(12.2)$ & 26.7 & $(23.7)$ & 13.6 & $(13.3)$ & $F=43.1^{* \star \star \star \star *}$ & $F<1.0$ \\
\hline $14 .^{\circ}$ & Those who are liked by everyone & 15.9 & $(12.7)$ & 23.9 & $(18.1)$ & 15.7 & $(7.8)$ & 24.8 & $(19.4)$ & $F=11.0^{* * *}$ & $F<1.0$ \\
\hline 15. & $\begin{array}{l}\text { Those who always mess around and } \\
\text { get into trouble }\end{array}$ & 61.9 & $(21.0)$ & 24.0 & $(23.8)$ & 30.9 & (23.5) & 8.9 & $(13.7)$ & $F=127.9^{\star \star \star \star \star}$ & $F=4.9^{*}$ \\
\hline $16 .^{\circ}$ & Those who make fun of people & 47.0 & (18.5) & 22.1 & (17.5) & 25.1 & (18.3) & 11.8 & (13.3) & $F=110.5^{\star * * * *}$ & $\mathbf{F}=5.0^{*}$ \\
\hline $17 .^{\circ}$ & Those who have very few friends & 31.5 & $(17.3)$ & 15.9 & (15.7) & 22.9 & $(19.7)$ & 15.4 & $(15.7)$ & $F=41.8^{* k * * *}$ & $F=2.4$ \\
\hline
\end{tabular}


18. Those who do strange things

19. Those who are your best friends

20. Those who bother people when they are trying to work

21. Those who get mad when they don't get their way

22. Those who don't pay attention to the teacher

23. Those who are rude to the teacher

24. Those who are unhappy or sad

26. Those who act like a baby

27. Those who are mean and cruel to other children

28. Those who often don't want to play

29. Those who give dirty looks

30. Those who want to show off in front of the class

31. Those who say they can beat everybody up

32. Those who aren't noticed much

33. Those who exaggerate and make up stories

34. Those who complain, nothing makes them happy

35. Those who always seem to understand things
25. Those who are especially nice

\begin{tabular}{|c|c|c|c|c|c|c|c|c|c|}
\hline 36.0 & $(16.1)$ & 19.2 & (14.3) & 23.3 & $(16.8)$ & 10.2 & $(10.4)$ & $F=63.0^{* * * * *}$ & $F<1.0$ \\
\hline 14.6 & (8.5) & 24.0 & $(12.9)$ & 20.6 & (9.2) & 24.8 & (13.7) & $F=16.3^{* * * *}$ & $F=1.2$ \\
\hline 45.0 & (18.7) & 20.0 & (17.1) & 22.4 & $(16.4)$ & 11.0 & $(12.5)$ & $F=114.7^{* * * * *}$ & $F=7.1^{\star *}$ \\
\hline 51.3 & $(23.4)$ & 17.6 & (15.3) & 30.1 & $(23.7)$ & 13.2 & $(14.2)$ & $F=147.6^{* * * * *}$ & $F=8.4^{* \star}$ \\
\hline 55.3 & (20.3) & 25.3 & $(23.7)$ & 28.1 & (23.2) & 15.3 & (19.6) & $F=82.0^{\star \star \star \star \star *}$ & $F=5.8^{*}$ \\
\hline 50.8 & $(26.0)$ & 19.0 & (22.8) & 25.0 & (17.1) & 11.1 & (17.1) & 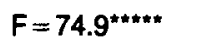 & $F=5.5^{*}$ \\
\hline 16.0 & (3.6) & 8.2 & (9.7) & 13.1 & (8.5) & 9.3 & $(11.1)$ & $F=22.9^{* \star \star \star * *}$ & $F=1.3$ \\
\hline 9.2 & $(8.0)$ & 17.1 & (14.1) & 16.8 & $(8.6)$ & 27.8 & (18.8) & $F=11.8^{* * *}$ & $F<1.0$ \\
\hline 30.2 & $(21.8)$ & 10.3 & (12.4) & 16.6 & $(12.6)$ & 9.5 & (12.3) & $F=89.6^{* * * * *}$ & $F=8.2^{* *}$ \\
\hline 41.0 & $(24.1)$ & 12.6 & $(14.0)$ & 14.3 & (11.1) & 7.6 & $(10.2)$ & $F=125.8^{\star \star \star \star \star *}$ & $F=19.4^{* * * * *}$ \\
\hline 13.6 & $(10.4)$ & 6.7 & (8.4) & 7.2 & (4.9) & 8.8 & $(8.4)$ & $F=19.0^{* * * * *}$ & $F=8.9^{* *}$ \\
\hline 38.5 & $(22.2)$ & 13.1 & $(13.1)$ & 17.7 & $(17.0)$ & 7.9 & $(10.3)$ & $F=117.5^{\star \star \star \star \star}$ & $\mathbf{F}=10.9^{\star \star \star}$ \\
\hline 44.5 & $(21.4)$ & 17.7 & $(18.8)$ & 16.0 & $(13.2)$ & 9.0 & (12.1) & $F=78.6^{* * * * *}$ & $F=11.2^{* * *}$ \\
\hline 56.9 & $(21.9)$ & 27.1 & $(22.1)$ & 26.3 & (22.6) & 9.4 & $(12.1)$ & $F=121.7^{\star \star \star \star \star \star}$ & $F=4.6^{*}$ \\
\hline 15.7 & $(13.6)$ & 10.1 & $(10.2)$ & 14.3 & $(10.2)$ & 13.8 & (12.7) & $F=8.4^{* *}$ & $F=1.8$ \\
\hline 36.3 & $(20.5)$ & 15.2 & (14.3) & 20.3 & (12.9) & 8.9 & $(10.5)$ & $F=110.8^{* \star \star \star \star \star}$ & $F=4.7^{\star}$ \\
\hline 26.1 & $(16.7)$ & 9.2 & $(10.3)$ & 13.7 & (12.7) & 7.8 & $(10.0)$ & $F=97.9^{\star \star \star \star \star \star}$ & $F=9.3^{* *}$ \\
\hline 12.3 & $(10.3)$ & 18.8 & $(15.9)$ & 13.7 & $(10.4)$ & 26.7 & $(18.7)$ & $F=12.0^{* * *}$ & $F=1.3$ \\
\hline
\end{tabular}

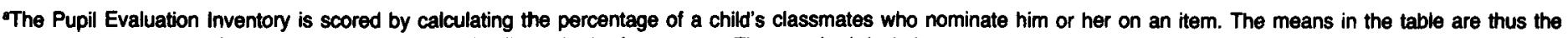
average percentages of classmates who nominated children in the four groups. The standard deviations are reported in parentheses.

${ }^{b}$ Hyperactive $\mathrm{N}=37$; nonhyperactive $\mathrm{N}=217$ except on items marked with an e, where hyperactive $\mathrm{N}=52 ;$ nonhyperactive $\mathrm{N}=251$

cHyperactive $\mathrm{N}=10$; nonhyperactive $\mathrm{N}=236$ except on items marked with an e, where hyperactive $\mathrm{N}=12 ;$ nonhyperactive $\mathrm{N}=272$

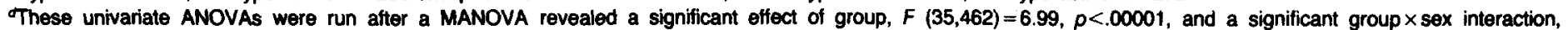

$F(35,462)=1.67, \rho<.05$. The degrees of freedom in each ANOVA were 1 and 496 , excepl on items marked with an $e$, where df $=1.583$.

items which were on both the first grade form and the upper form of the sociogram.

$" p<.05, " p<.01, " * * p<.001, " * * " p<.0001, " * * * * p<.00001$. 
quently seriously limited. ${ }^{62}$ In clinical practice, information regarding learning difficulties should be obtained because treatment must include a focus on learning problems, if present, as well as problematic social behaviors.

One question that has yet to be resolved is whether ADD children who are functioning below grade level academically are doing so because of their ADD or because they have a concurrent learning disability. This question for an individual child can only be answered by (1) conducting a standard psychoeducational assessment of the child's intellectual and cognitive performance and academic achievement, and (2) treating the ADD and monitoring what happens to the child's academic achievement with successful control of the ADD symptoms. If the assessment fails to reveal a significant discrepancy between intellectual potential and academic achievement, by definition the child does not have a learning disability. If the assessment does reveal a difference between potential and achievement and therefore a learning disability diagnosable in accordance with local school-district policy, then placement in an LD resource room at school is something the practitioner should help the parents seek. The major utility outside of research settings in making a determination of whether an ADD child has a concurrent learning disability is to obtain whatever extra educational intervention the school can provide. Pediatricians need to be aware that, as with ADD, there is no test that can be given to determine why a child has a learning disability or what the precise nature of that disability is. Tests can only tell us whether intellectual potential, defined by standardized IQ tests, is being met in achievement, also defined by standardized achievement tests. Further discussion of the diagnosis and treatment of learning disabilities is beyond the scope of this chapter, but informative discussions are available. ${ }^{89}$

\section{ETIOLOGY}

\section{The Construct of Brain Damage}

During the 1950s and 1960s the prevailing assumption was that hyperactivity resulted from brain damage. Studies on World War I veterans with confirmed brain injury often showed a behavioral syndrome which included difficulties in abstract thinking and in attentional processes, and emotional lability. Because children labeled hyperactive or learning-disabled exhibited similar behaviors, their disturbances were also assumed to result from brain damage, and the notion of brain damage as a cause of hyperactivity and learning disabilities persisted. When it gradually became clear that no evidence of gross brain damage was apparent in the majority of 
these children, ${ }^{85}$ the term "minimal brain damage" came into prominence.

The concept of minimal brain damage implied that brain damage was so slight that its existence could not be demonstrated with traditional measures of gross brain damage. Thus "hard" signs of neurological damage were usually not found in hyperactive children, but many hyperactive children had a greater number of "soft" or equivocal signs of neurological damage..$^{90}$ Many hyperactive children, however, did not evidence even equivocal signs of neurological damage, ${ }^{11}$ and a history of perinatal events presumed to be associated with minimal brain damage could not be demonstrated in most cases. ${ }^{92}$ Finally, neurological and behavioral variables did not relate to one another in a manner that supported a construct of minimal brain damage. ${ }^{57}$

Because no minimal brain damage could be demonstrated it was assumed that hyperactivity must result from a minimal brain $d y s-$ function (MBD) that was even more difficult to detect than minimal brain damage. ${ }^{93} \mathrm{MBD}$ was often inferred on the basis of neurological soft signs. The notion that ADD-H is correlated with a dysfunction in the central nervous system (CNS) is widely accepted and has been the stimulus for a large body of research, the current thrust of which is to discover both the nature of that dysfunction at cognitive and physiological levels and its etiological correlates. Assessment of neurological status using soft signs as indices, however, has not proven useful in the study of ADD. ${ }^{94,95}$ If the term MBD is used only among professionals as a probable description of the current state of a child's CNS, it may be heuristically useful. Nonetheless, neither the precise nature of this dysfunction nor the etiological variables associated with it are yet known. To say that a child suffers from minimal brain dysfunction is to describe his or her problem rather than to explain it. The practitioner needs to be particularly careful with the use of the term MBD. Any label that includes the word "brain" can have connotations for parents, teachers, and uninformed professionals that go far beyond those that may be intended. ${ }^{85}$

The brief discussion of etiology that follows is intended to give the reader a brief introduction to some of the research being conducted on etiology. A considerably more extensive discussion of etiology is available in Ross and Ross. ${ }^{96}$ As Sleator discusses in Chapter 2 , none of the procedures, techniques or results from these studies have any implications for the practicing pediatrician.

\section{Perinatal Variables}

Since the late 1950s there have been frequent suggestions that behavioral and learning problems often result from a variety of biological disturbances in pregnancy and birth. The phrase "continuum of 
reproductive causality" has been used to imply not only that severe biological disturbances result in profound psychological problems (for example, children with extremely low birth weights, below 1500 grams, are often mentally retarded), but also that less serious deviations of pregnancy can result in a variety of less profound behavior disorders. ${ }^{97,98}$ In retrospective interviews, mothers of hyperactives were more likely than mothers of control children to report bleeding in pregnancy, toxemia, high blood pressure, low birth weight, and anoxia. ${ }^{99}$ When the same information was obtained from actual medical records, however, substantially fewer differences were reported. ${ }^{92}$ Because perinatal disturbances cannot be identified for all ADD children, ${ }^{91}$ at the least, perinatal disturbances must interact with other variables if they are to result in ADD.

Several prospective studies have examined the relationship between perinatal disturbances and later behavior and learning disorders. The Kauai study ${ }^{100}$ followed 1000 children from pregnancy to the age of 10. No relationship was found between (1) 60 selected complications or events that could have occurred during prenatal, labor, delivery, and neonatal periods; and (2) teacher-rated presence of symptoms associated with hyperkinesis at age 10 . A second study, the Educational Follow-up Study (EFS), is following 1600 of the children originally included in the Collaborative Project of the National Institute of Neurological Diseases and Stroke. ${ }^{101} \mathrm{~A}$ multiple regression analysis of 8 subclasses of 76 perinatal factors and teacher identification of behavior problems at age 10 revealed that perinatal factors such as maternal reproductive and mental history, variables related to the target pregnancy and delivery, and other neonatal factors accounted for only 13 percent of the variance of teacher-rated problems. Similar results with another part of the NINDS sample were reported by Nichols and Chen. ${ }^{102}$

In summary, there are small mean differences between ADD and control children in the reported frequencies of a variety of perinatal disturbances, but their use to predict diagnostic group membership or degree of behavior disturbance is not possible except in extreme cases. ${ }^{101}$ It is not clear that perinatal variables are exclusively related to ADD. The EFS results, for example, suggest that they may be weakly related to behavior and learning disorders in general. Similarly, Nichols and $\mathrm{Chen}^{102}$ found that frequency of maternal smoking during pregnancy was related both to ADD and to learning disabilities.

\section{Minor Physical Anomalies}

Several investigators have examined minor physical anomalies, a set of neurologically related variables that appear to be more predictive of behavioral disorders than the perinatal factors already discussed. 
There are 17 anomalies (e.g., epicanthus, low-set ears, curved fifth finger, elongated middle toe) that are formed in early fetal development, known to be affected by genetic, toxic, and other environmental factors, and found in children with Down's syndrome and a wide variety of other behavior disorders. ${ }^{101,103}$ They are presumably caused by whatever agent causes the neurological dysfunction later manifested in behavioral and learning disorders. In addition, there is some evidence that there may be a genetic component to the anomalies. ${ }^{104}$ Study of the anomalies' relationship with behavioral and neurological variables might thus implicate potential etiological factors in ADD.

Several studies have revealed relatively strong correlations (ranging from $r=.35$ to $r=.67$ ) between the number of anomalies (total anomaly score) and teacher or peer ratings and direct observations of ADD and other behavior problems. ${ }^{105-107}$ The lower of these two correlations is the more commonly reported. Nonetheless, the relationship between this single predictor and criterion variables is considerably larger than shown by the entire group of perinatal variables previously discussed.

Similarly, Rapoport and her colleagues ${ }^{103}$ examined minor physical anomalies in children diagnosed as hyperactive and reported the following seven findings:

1. Hyperactive children had a higher average anomaly score, 3.58, than comparison children with neurotic problems, 2.53. ${ }^{109}$

2. The number of anomalies was positively correlated with teacher ratings on the conduct $(r=.35)$ and the hyperactivity $(r=.28)$ factors of the CTRS. ${ }^{108}$

3. The high-anomaly children were more likely (57 percent) than low-anomaly children ( 19 percent) to have a father who remembered himself to have been hyperactive as a child. ${ }^{104}$

4. Mothers of high-anomaly children were more likely (53 percent) than mothers of low-anomaly children (18 percent) to have had obstetrical complications during pregnancy, especially bleeding during the first trimester. ${ }^{108}$

5. Anomaly score was unrelated to the presence of neurological signs and EEG abnormalities. ${ }^{104}$

6. Hyperactive children with high-anomaly scores were more likely ( 88 percent) than low-anomaly hyperactives (35 percent) to have been considered problems by their parents before the age of 3 years. ${ }^{103}$

7. There was a significant correlation $(r=.38)$ between anomaly score and plasma level of dopamine- $\beta$-hydroxylase, the enzyme that converts dopamine to norepinephrine. ${ }^{108}$ A stepwise discriminant analysis using age of onset, plasma level of dopamine- $\beta$-hydroxylase, paternal history of hyperactivity, 
and maternal history of obsterical complications predicted level of anomaly score (high or low) with false positive and false negative rates of only 7 percent and 11 percent, respectively. ${ }^{103}$

Although these data suggest that a major biological subgroup of ADD has been identified, additional research is necessary. The fact that no relationship was identified between anomaly scores and signs of neurological dysfunction contradicts the basic assumption underlying the study of the anomalies-that is, whatever caused the anomaly also caused a neurological dysfunction that resulted in ADD. Similarly, the correlations among various measures were not always consistent with the theoretical relationship among anomalies, dopamine- $\beta$-hydroxylase level, and behavior. In addition, there was a very high false positive rate when a high anomaly score alone was used to infer deviance. ${ }^{103}$ Finally, in one study ${ }^{104}$ the mean anomaly score was higher for children labeled unsocialized aggressive (4.0) than for children labeled hyperactive (3.58), suggesting that anomalies are not limited to a role in ADD. ${ }^{101}$

Rapoport's studies indicated that both paternal history of hyperactivity and maternal prenatal complications were related to anomaly score but the relationships were separate. They speculated that the relationship between anomalies and hyperactivity was a genetic one "frequently mimicked (phenocopied) by an insult early in pregnancy. ${ }^{\prime 104}$ These two etiologically distinct subgroups may show different relationships with other etiologic, mediating, and behavioral/ cognitive variables, and should be studied with this in mind. This line of research appears promising because it attempts to examine empirically defined subgroups of ADD. If this is to prove fruitful, however, it will be necessary to postulate and then demonstrate comprehensive theoretical relationships linking specific anomalies, genetic or teratogenic mechanisms, resulting neurological dysfunction, and behavior patterns and diagnostic categories. Further, studies that investigate the possible mediating role of aggression in these linkages need to be conducted.

\section{Genetic Variables}

Studies with less than optimal designs have provided evidence suggestive of genetic involvement in hyperactivity, but the research necessary to confirm this involvement has not been conducted. For example, it has been shown that there is an increased prevalence of sociopathy, alcoholism, hysteria, and retrospective diagnosis of hyperactivity among the biological parents but not among the adoptive 
parents of hyperactive children. ${ }^{109,110}$ An increased prevalence of hyperactivity has been reported among full siblings (as opposed to half siblings) and among second-degree relatives of hyperactive children. ${ }^{111}, 112$ ADD may be genetically linked to "continuous" schizophrenia, ${ }^{113}$ but this hypothesized connection will not be clarified until ongoing studies of children at risk are completed.

Other researchers have argued that evidence for heritability of activity level in humans and other animals suggests that hyperactivity may have a genetic etiology. For example, parental ratings of activity level are higher for monozygotic than for dizygotic twins. ${ }^{114}$ Given the current conceptualization of hyperactivity as a dysfunction in attention rather than activity level, such extrapolations seem unwarranted.

It is clear that either separate twin studies or genetic marker studies must be conducted before a final conclusion can be reached regarding genetic involvement in hyperactivity. ${ }^{115}$ Subgroup analysis in such studies is more likely to yield useful information than are global questions regarding heritability. ${ }^{116}$ Note, for example, that the frequency of retrospective diagnosis of parental hyperactivity was considerably higher in Rapoport's high-anomaly children than in her low-anomaly children (see the discussion in the preceding section) or groups not separated on this variable. ${ }^{109}$ Finally, the nature of the putative genetic transmission in hyperactivity is unclear. Simple recessive, dominant, or sex-linked explanations do not match available data, and some type of polygenetic mechanism seems likely. ${ }^{96,111}$

\section{Neurochemical Variables}

Several hypotheses have been advanced relating the function of the CNS neurotransmitters serotonin, norepinephrine, and dopamine to ADD. Studies usually assess the levels of transmitter metabolites in urine or cerebrospinal fluid or measure blood levels of the transmitters, their precursors, or relevant enzymes. ${ }^{117,}{ }^{118}$ Such studies have failed to indicate a role for serotonin in hyperactivity. ${ }^{119}$ In addition and contrary to early speculation, ${ }^{120}$ there appears to be no evidence supporting a role for norepinephrine in hyperactivity. ${ }^{41}$

Dopamine is presumed to play an important role in the regulation of motoric and aggressive behavior, ${ }^{121}$ and it has been postulated that hyperactive children have low brain levels of dopamine or some specific damage or dysfunction in dopaminergic pathways in the CNS. ${ }^{122,123}$ Shaywitz and associates ${ }^{119}$ compared cerebrospinal fluid levels of homovanillic acid, a major metabolite of dopamine, in a small group of hyperactive children and controls and found tentative indications of low CNS dopamine levels in hyperactives. Shay- 
witz and associates noted, ${ }^{122}$ however, the need for replication of their results with a larger sample of children.

Thus despite considerable interest in this approach and despite the challenging theoretical implications, there is not yet clear information regarding how hyperactive children differ from controls in levels of CNS neurotransmitters. The major obstacle to research in this area is that brain levels of neurotransmitters cannot be directly measured in humans and must consequently be inferred from cerebrospinal fluid levels or peripheral measures. If techniques for measuring brain levels of neurotransmitters were developed, this area of research might become especially promising.

\section{Socio-Environmental Influences}

Drawing on the literatures regarding child-parent temperament interactions and social learning theory, some authors have speculated that ADD results in part from the nature of the child's interactions with his or her environment, especially with significant others. ${ }^{96} \mathrm{Al}-$ though several observational studies have shown that mothers exerted more control over their ADD children and imposed greater structure on their task performance than mothers of comparison children, ${ }^{124,125}$ and that teachers exhibited a much higher frequency of controlling statements to hyperactive boys than to control boys, ${ }^{126}$ the directionality of these relationships is unclear.

The major approach to the socio-environmental issue has employed multivariate techniques to examine the relationship among environmental variables and measures of symptomatology in ADD children. Loney and her colleagues ${ }^{\prime 1,12 /}$ examined the relationship between their two symptom factors of aggression and hyperactivity and environmental variables derived primarily from chart-raters' evaluations of intake and assessment information. A stepwise multiple regression with score on the aggression factor as the criterion yielded a multiple correlation of .55 for father's love-to-hostility rating, mother's autonomy-to-control rating, and parental SES, suggesting that high levels of aggression were associated with low SES, hostile fathers, and undercontrolling mothers. The only variable significantly related to score on the hyperactivity factor was the mother's autonomy-to-control rating. In addition, chart-rater evaluation of disharmony in the parent-child relationship at referral was positively associated with the aggression factor $(r=.47)$ but not with the hyperactivity factor. Interestingly, chart rating of parental disturbance (e.g., social incompetence, heavy drinking, police contacts, mental illness) was positively correlated with the aggression factor but not with the hyperactivity factor. ${ }^{71}$ 
A somewhat different picture of the relationship between these environmental factors and symptomatology was obtained when environmental measures taken at referral and measures of symptomatology at follow-up were examined. ${ }^{71}$ Mother and father autonomyto-control, family SES, and disharmony in the parent-child relationship at referral all predicted score on the aggression factor at 5-year follow-up. Degree of hyperactivity at follow-up was predicted by mother's love-to-hostility rating, father's autonomy-to-control and love-to-hostility ratings, SES parental disturbance, disharmony in the parent-child relationship, and disharmony in the motherfather relationship. Behavior problems in general at follow-up were predicted by disharmony in the parent-child relationship, parental disturbance, and a change (from referral) of parent figure. Change of parent figure also predicted degree of aggression and hyperactivity at follow-up.

Similar results were reported in the Kauai follow-up study described earlier. ${ }^{100}$ The relationships were examined between groups of children defined as hyperkinetic and overaggressive on the basis of teacher ratings and three variables of interest here: (1) SES, (2) educational stimulation (opportunities and structures provided in the home for educationally stimulating activities), and (3) emotional support (stable home, both parents present, affection, approval and reasoning used in parent-child interaction). Compared to homes with average ratings on these variables, the prevalence of "hyperkinesis" was increased by 77 percent in homes with below average ratings of educational support. The comparable increases in prevalence of overaggressiveness were 240 percent and 311 percent. "Hyperkinesis" was not related to SES, but overaggressiveness was strongly related to SES.

Although firm conclusions are prohibited because the data are correlated and are based on chart or other ratings relatively far-removed from actual behavior, these studies suggest that measures of the quality of the home environment are correlated with outcome in children who show symptoms of ADD and aggression. In both sets of studies the relationships were clearly stronger for aggressive than for ADD symptoms, showing again the level of aggressive symptomatology provides important information that is not available from examination of hyperactive symptomatology alone. Both at referral and at follow-up, there was a strong association between aggressive symptoms and disturbances in the home environment. The same association was only apparent at follow-up for ADD symptoms, suggesting that a considerable period of time must pass before the association between ADD symptoms and the home situation becomes as strong as the association between aggressive symptoms and the home situation. The causal nature of the relationship between home 
environment and symptomatology cannot be determined from these correlational data. The relationship is no doubt a reciprocal one with severe symptoms causing disruption in the family and disruption in the family in turn exacerbating symptoms, and research addressing this issue directly is badly needed.

For example, the author and a colleague have recently begun to study the effects of ADD children's behavior on their parents' alcohol consumption. We speculated that the relationship between ADD in children and alcoholism in fathers, as well as in grown-up ADD children, may be at least in part an environmental, reciprocally influenced relationship. Our first study involved college students and child actors and showed that immediate, subsequent alcohol consumption increased by 40 percent over a control condition when the students had interacted with a child who behaved as a typical ADD child. ${ }^{128}$ These results suggest that ADD children's behavior may cause or at least exacerbate problems in their parents. At the least, these data certainly highlight the need for a focus on parent-child interactions and other familial variables in the treatment of hyperactive children (see the discussion of parent training in Chapter 5).

\section{Summary}

There is inconclusive but accumulating evidence for a variety of biological factors in the etiology of some ADD children. Environmental influences do not appear to cause $\mathrm{ADD}$, but they may exert a strong influence on the nature and severity of the problem in many children. The research just reviewed suggests, however, that no single variable accounts for all or even most cases of ADD. As research designs continue to include more fine-grained analyses of subgroup patterns, the relationships between different etiological factors and empirically defined subgroups of ADD children may be elucidated. It seems likely that such studies will reveal that most cases of ADD are determined through interactions among these etiological variables.

\section{REFERENCES}

1. Laufer M, Denhoff E, Solomons G: Hyperkinetic impulse disorder in children's behavior problems. Psychosom Med 19:38-49, 1957.

2. Douglas VI: Attentional and cognitive problems, in Rutter M (ed): Developmental Neuropsychiatry. New York, Guilford, 1983, pp 280-329.

3. Barkley RA: Guidelines for defining hyperactivity in children: Attention deficit disorders with hyperactivity, in Lahey BB, Kazdin AE (eds): 
Advances in Clinical Child Psychology, Vol. 5. New York, Plenum, 1982, pp 137-180.

4. Routh D: Developmental and social aspects of hyperactivity, in Whalen C, Henker B (eds): Hyperactive Children: The Social Ecology of Identification and Treatment. New York, Academic Press, 1980.

5. Conners C: A teacher rating scale for use in drug studies with children. Amer J Psychiat 126:884-888, 1969.

6. Goyette $\mathrm{CH}$, Conners $\mathrm{CK}$, Ulrich RF: Normative data on revised Conners parent and teacher rating scales. J Abnorm Child Psychol 6:221236, 1978.

7. Werry J, Sprague R, Cohen M: Conner's teacher rating scale for use in drug studies with children-An empirical study. J Abnorm Child Psychol 3:217-229, 1975.

8. Achenbach TM: The Child Behavior Profile: I. Boys ages 6-11. J Consult Clin Psychol 46:478-488, 1978.

9. Achenbach TM, Edelbrock CS: The Child Behavior Profile. II. Boys aged 12-16 and girls aged 6-11 and 12-16. J Consult Clin Psychol 46:223-233, 1979.

10. Quay HC, Peterson DR: Interim Manual for the Revised Behavior Problem Checklist. Unpublished manuscript, University of Miami, 1983.

11. Ullman RK, Sleator EK, Sprague RL: A new rating scale for diagnosis and monitoring of ADD children. Psychopharm Bull 20:160, 1984.

12. Pelham WE, Atkins MS, Murphy HA: ADD with and without hyperactivity: Parent, teacher, and peer rating correlates, in Pelham WE (chair): DSM-III Category of attention deficit disorder: Rationale, operational and correlates. Symposium presented at the annual meetings of the American Psychological Association, Los Angeles, September, 1981.

13. Pelham WE, Atkins MS, Murphy HS, Swanson JM: A rating scale for the diagnosis of attention deficit disorders: Teacher norms, factor analyses, and reliability. Manuscript submitted for publication, 1985.

14. Douglas VI: Stop, look and listen: The problem of sustained attention and impulse control in hyperactive and normal children. Canad $\mathrm{J} \mathrm{Be}$ hav Sci 4:259-282, 1972.

15. Stewart M, Pitts F, Craig A, Dieruf W: The hyperactive child syndrome. Amer J Orthopsychiat 36:861-867, 1966.

16. Barkley RA, Ullman DG: A comparison of objective measures of activity and distractibility in hyperactive and nonhyperactive children. J Abnorm Child Psychol 3:213-244, 1975.

17. Firestone $\mathbf{P}$, Martin J: An analysis of the hyperactive syndrome: A comparison of hyperactive, behavior problem, asthmatic and normal children. J Abnorm Child Psychol 1:261-274, 1979.

18. O'Leary S, Pelham W, Rosenbaum A, Price G: Behavioral treatment of hyperkinetic children: An experimental evaluation of its usefulness. Clin Pediat 15:511-515, 1976.

19. Abikoff $\mathrm{H}$, Gittelman-Klein R, Klein DF: Validation of a classroom observational code for hyperactive children. J Consul Clin Psychol 45:772-783, 1977.

20. Campbell SB, Werry JS: Attention deficit disorders (hyperactivity), in 
Quay HC, Werry JS (eds): Psychopathological Disorders of Childhood, ed 3. New York, Wiley, in press.

21. Porrino LJ, Rapoport JL, Behor D, Sceery W, Ismond DR, Bunney WE Jr: A naturalistic assessment of the motor activity of hyperactive boys: Comparison with normal controls. Arch Gen Psychiat 40:681, 1983.

22. Swanson J, Kinsbourne $M$ : The cognitive effects of stimulant drugs on hyperactive (inattentive) children, in Hale G, Lewis M (eds): Attention and the Development of Cognitive Skills. New York, Plenum, 1979.

23. Rosenthal $R$, Allen $T$ : An examination of the attention, arousal and kearning dysfunctions of hyperactive children. Psychol Bull 85:689-716, 1978.

24. Whalen CK, Henker B, Collins BE, Finck D, Dotemoto S: A social ecology of hyperactive boys: Medication effects in structured classroom environments. J Applied Behav Analys 12:65-68, 1979.

25. Charles L, Schain RJ, Zelnicker T, Guthrie D: Effects of methylphenidate on hyperactive children's ability to sustain attention. Pediatrics 64:412, 1979.

26. Pelham WE: Selective attention deficits in poor readers? Dichotic listening, speeded classification, and auditory and visual central and incidental learning tasks. Child Develpm 50:1050-1061, 1979.

27. Hallahan DP: Distractibility in the learning-disabled child, in Cruckshank WM, Hallahan DP (eds): Perceptual and Learning Disabilities in Children, Vol. 2. Research and Theory. Syracuse, NY, University Press, 1975.

28. Kupietz S, Richardson E: Children's vigilance performance and inattentiveness in the classroom. J Child Psychol Psychiat 19:145-154, 1978.

29. Douglas V, Peters K: Toward a clearer definition of the attentional deficits of hyperactive children, in Hale G, Lewis M (eds): Attention and the Development of Cognitive Skills. New York, Plenum, 1979.

30. Pelham WE: Attention deficits in hyperactive and learning-disabled children: A reconceptualization. Except Educ Quart 2:13-24, 1981.

31. Cohen NJ, Douglas VI: Characteristics of the orienting response in hyperactive and normal children. Psychophysiology, 9:238-245, 1972.

32. Sykes DH, Douglas VI, Weiss G, Minde KK: Attention in hyperactive children and the effect of methylphenidate (Ritalin). J Child Psychol Psychiat 12:129-139, 1971.

33. Sykes DH, Douglas VI, Morgenstern G: Sustained attention hyperactive children. J Child Psychol Psychiat 14:213-220.

34. Campbell SB, Douglas VI, Morgenstern G: Cognitive styles in hyperactive children and the effect of methylphenidate. J Child Psychol Psychiat 12:55-67, 1971.

35. Schnedler RW, Pelham WE, Bender ME, Passe JE: Capacity limitations in the attentional processes of hyperactive children. Paper presented at the annual meetings of the American Psychological Association, Washington, DC, August 1982.

36. Sergeant J: In search of processing deficits of attention in ADD-H children, in Bloomingdale L, Swanson J, Klorman R (eds): Attention Deficit Disorders: New Directions, Vol. 4. New York, Spectrum, in press. 
37. Pelham WE: Childhood hyperactivity: Diagnosis, etiology, nature, and treatment, in Gatchel R, Baum A, Singer J (eds): Clinical Psychology and Behavioral Medicine: Overlapping Discipline, Vol. 1 of Baum A, Singer J (eds.): Handbook of Psychology and Health. Hillsdale, NJ, Erlbaum, 1982.

38. Sergeant JA, Scholten CA: On resource strategy limitations in hyperactivity: Cognitive impulsivity reconsidered. J Child Psychol Psychiat 26:97, 1985.

39. Sergeant JA, Scholten CA: On data limitations in hyperactivity. J Child Psychol Psychiat 26:111, 1985.

40. Hastings JE, Barkley RA: A review of psychophysiological research with hyperactive children. J Abnorm Child Psychol 6:413-448, 1978.

41. Ferguson B, Pappas B: Evaluation of physiological, neurochemical and animal models of hyperactivity, in Trites $R$ (ed): Hyperactivity in children. Baltimore, University Park Press, 1979.

42. Donchin E (ed): Cognitive Psychophysiology: Event Related Potentials and the Study of Cognition, Vol. 1. Hillsdale, NJ, Erllbaum, 1984.

43. Klorman R, Salzman LF, Bolgstedt AD: Brain event-related potentials as a tool for evaluating cognitive deficits in attention deficit disorder and stimuland therapy, in Bloomingdale L (ed): Attention Deficits Disorder, Vol. 3. New York, Spectrum, in press.

44. Callaway E, Halliday R, Naylor H: Hyperactive children's event-related potentials fail to support underarousal and maturational-lag theories. Arch Gen Psychiat 40:1243, 1983.

45. Abikoff $H$, Gittelman $R$, Klein DF: Classroom observation code for hyperactive children: A replication of validity. J Consult Clin Psychol 48:555, 1980.

46. Atkins MS, Pelham WE, Licht MH: A comparison of objective classroom measures and teacher ratings of attention deficit disorders. J Abnorm Child Psychol 13:155, 1985.

47. Kagan J: Reflection-impulsivity: The generality and dynamics of conceptual tempo. J Abnorm Psychol 71:14-24, 1966.

48. Bentler PM, McClain J: A multitrait-multimethod analysis of reflectionimpulsivity. Child Develpm 47:218-226, 1976.

49. Milich R, Kramer J: Reflections on impulsivity: An empirical investigation of impulsivity as a construct, in Gadow K, Bialer I (eds): Advances in Learning and Behavioral Disabilities, Vol. 3. Greenwich, Conn, JAI Press, 1984, pp 57-94.

50. Sergeant J, Velthoven R, Virginia A: Hyperactivity, impulsivity and reflectivity: An examination of their relationship and implications for clinical child psychology. J Child Psychol Psychiat 20:47-60, 1979.

51. Lahey BB, Stempniak M, Robinson EJ, Tyroler M: Hyperactivity and learning disabilities as independent dimensions of child behavior problems. J Abnorm Psychol 87:333-340, 1978.

52. Pelham WE, Atkins MS, Murphy HA: ADD with and without hyperactivity: Parent, teacher and peer rating correlates, in Pelham $W$ (chair): DSM-III Category of attention deficit disorder: Rationale, operational and correlates. Symposium presented at the annual meeting of the American Psychological Association, Los Angeles, September 1981. 
53. Kendall $P$, Wilcox L: Self-control in children: Development of a rating scale. J Consult Clin Psychol 47:1020-1027, 1979.

54. Loper A, Hallahan D: A comparison of the reliability and validity of the standard MFF and MFF20 with learning-disabled children. J Abnorm Child Psychol 8:377-384, 1980.

55. Achenbach TM, Edelbrock CS: The classification of child psychopathology: A review and analysis of empirical efforts. Psychol Bull 85:12751301, 1978.

56. Quay HC: Classification, in Quay H, Werry J (eds): Psychopathological Disorders of Childhood, ed 2. New York, Wiley, 1979.

57. Werry JS: Studies on the hyperactive child. IV. An empirical analysis of the minimal brain dysfunction syndrome. Arch Gen Psychiat 19:9$16,1968$.

58. Langhorne J, Loney J, Paternite C, Bechtold H: Childhood hyperkinesis: A return to the source. J Abnorm Psychol 85:201-210, 1976.

59. Routh D, Roberts R: Minimal brain dysfunction in children: Failure to find evidence for a behavioral syndrome. Psychol Reports 31:307-314, 1972.

60. Rutter M: Behavioral studies: Questions and findings on the concept of a distinctive syndrome, in Rutter M (ed): Developmental Neuropsychiatry. New York, Guilford, 1983, pp 259-279.

61. Pelham WE, Atkins MS, Murphy HS, White KS: Operationalization and validity of attention deficit disorders, in Pelham $W$ (chair): Toward the objective diagnosis of hyperactivity and attention deficit disorders. Symposium presented at the annual meeting of the Association for the Advancement of Behavior Therapy, Toronto, November 1981.

62. Ross A, Pelham W: Child psychopathology, in Rosenzweig M, Porter L (ed): Annual Review of Psychology, Vol. 32. Palo Alto, Annual Reviews, 1981.

63. Stewart $M$, Cummings $C$, Singer $C$, deBlois $C$ : The overlap between hyperactive and unsocialized aggressive children. J Child Psychol Psychiat 22:35-46, 1981.

64. Prinz R, Conner P, Wilson C: The intertwined dimensions of aggression and hyperactivity in childhood. J Abnorm Child Psychol 9:191202, 1981.

65. Pelham WE, Bender ME: Peer relationships in hyperactive children: Description and treatment, in Gadow K, Bialer I (eds): Advances in Learning and Behavioral Disability. Vol. 1. Greenwich, Conn, JAI Press, 1982.

66. Loney J, Langhorne J, Paternite C: An empirical basis for subgrouping the hyperkinetic/MBD syndrome. J Abnorm Psychol 87:431-439, 1978.

67. Milich R, Loney J, Landau S: The independent dimensions of hyperactivity and aggression: $A$ replication and further validation. Unpublished manuscript, University of Iowa, 1982.

68. O'Leary SG, Steen P: Independent assessment of hyperactivity and aggression in hyperactive children, in Lahey B (chair): Is there an independent syndrome of hyperactivity in children? Symposium presented at the annual meeting of the American Psychological Association, Montreal, September 1980. 
69. Loney J, Milich R: Hyperactivity, inattention, and aggression in clinical practice, in Wolraich $M$, Routh D (eds): Advances in Behavioral Pediatrics, Vol. 2. Greenwhich, Conn, JAI Press, in press.

70. Milich $\mathrm{R}$, Loney J: The role of hyperactive and aggressive symptomatology in predicting adolescent outcome among hyperactive children. J Pediat Psychol 4:93-112, 1979.

71. Paternite C, Loney J: Childhood hyperkinesis: Relationships between symptomatology and home environment, in Whaley C, Henker B (eds): Hyperactive Children: The Social Ecology of Identification and Treatment. New York, Academic Press, 1980.

72. Milich $\mathrm{R}$, Landau S: The role of social status variables in differentiating subgroups of hyperactive children, in Bloomingdale L, Swanson J, Klorman R (eds): Attention Deficit Disorders: New Directions, Vol. 4. New York, Spectrum, in press.

73. Murphy DA, Pelham WE, Milich R: Normative and validity data on the Iowa Conners Teachers Rating Scale. Paper accepted for presentation at the annual meeting of the Association for Advancement of Behavior Therapy, Houston, November 1985.

74. Johnston $\mathrm{CJ}$, Pelham WE: Teacher ratings predict peer ratings of aggression at 3-year follow-up in boys with attention deficit disorder with hyperactivity. J Consult Clin Psychol, in press.

75. Cowen E, Pederson A, Babigian H, et al: Long-term follow-up of early detected vulnerable children. J Consult Clin Psychol 41:438-446, 1973.

76. Huesmann LR, Eron LD, Lefkowitz MM, Walder LO: Stability of aggression over time and generations. Develpm Psychol 20:995, 1984.

77. Roff M, Sells S, Golden M: Social Adjustment and Personality Development in Children. Minneapolis, University of Minnesota Press, 1972.

78. Hartup WW: Peer relations, in Hetherington EM (ed): Socialization, Personality, and Social Development, Vol. 4 of Mussen PH (ed): Handbook of Child Psychology, ed 4. New York, Wiley, 1983, pp 103-196.

79. Milich R, Landau S: Socialization and peer relations in hyperactive children, in Gadow KD, Bialer I (eds): Advances in Learning and Behavioral Disabilities, Vol. 1. Greenwich, Conn, JAI Press, 1982, pp 283340.

80. Campbell S, Paulauskas S: Peer relations in hyperactive children. J Child Psychol Psychiat 20:233-246, 1979.

81. Klein A, Young R: Hyperactive boys in their classroom: Assessment of teacher and peer perceptions, interactions and classroom behavior. J Abnorm Child Psychol 7:425-442, 1979.

82. Milich R, Fitzgerald G: Validation of inattention/overactivity and aggression ratings with classroom observations. J Consult Clin Psychol 53:139, 1985.

83. Pekarik G, Prinz R, Liebert D, et al: The pupil evaluation inventory: A sociometric technique for assessing children's social behavior. J Abnorm Child Psychol, 4:83-97, 1976.

84. Safer DJ, Allen RP: Hyperactive Children: Diagnosis and Management. Baltimore, University Park Press, 1976.

85. Ross AO: Psychological Aspects of Learning Disabilities and Reading Disorders. New York, McGraw-Hill, 1976. 
86. Lambert $\mathrm{N}$, Sandoval J: The prevalence of learning disabilities in a sample of children considered hyperactive. J Abnorm Child Psychol 8:3351, 1980.

87. Ackerman PT, Dykman RA: Automatic and effortful information-processing deficits in children with learning and attention disorders. Topics Learn Disabil July:12-22, 1982.

88. Dykman RA, Ackerman PT, McCray DS: Effects of methylphenidate on selective and sustained attention in hyperactive, reading-disabled and presumably attention-disordered boys. J Nerv Ment Dis 168:745, 1980.

89. Torgesen JK, Wong B (eds): Psychological and Educational Perspectives on Learning Disabilities. New York, Academic Press, in press.

90. Werry J, Minde K, Guzman A, et al: Studies on the hyperactive child. VII. Neurological status compared with neurotic and normal children. Amer J Orthopsychiat 42:441-451, 1972.

91. Dubey DR: Organic factors in hyperkinesis: A critical evaluation. Amer J Orthopsychiat 46:353-366, 1976.

92. Minde K, Webb G, Sykes D: Studies on the hyperactive child. VI. Prenatal and paranatal factors associated with hyperactivity. Develpm Med Child Neurol 10:355-363, 1968.

93. Rie H, Rie E: Handbook of Minimal Brain Dysfunctions. New York, Wiley, 1980.

94. Shafer SQ, Shaffer D, O'Conner PA, Stockman Cl: Hard thoughts on neurological "soft signs," in Rutter M (ed): Developmental Neuropsychiatry. New York, Guilford, 1983, pp 133-143.

95. Shaffer D, O'Conner PA, Shafer SQ, Piapis S: Neurological "soft signs": Their origins and significance for behavior, in Rutter $M$ (ed): Developmental Neuropsychiatry. New York, Guilford, 1983, pp 144 163.

96. Ross DM, Ross SA: Hyperactivity: Current Issues, Research, and Theory, ed 2. New York, Wiley, 1982.

97. Passamanick $B$, Knobloch $\mathrm{H}$ : Brain damage and reproductivity casualty. Amer J Orthopsychiat 30:298-305, 1960.

98. Knobloch H, Passamanick B: Prospective studies on the epidemiology of reproductive casualty: Methods, findings and some implications. Merrill-Palmer Quart 12:27-43, 1966.

99. Werry J, Weiss G, Douglas V: Studies on the hyperactive child. I. Some preliminary findings. Canad Psychiat Assn J 9:120-130, 1964.

100. Werner EE, Bierman J, French F: The Children of Kauai. Honolulu, University of Hawaii Press, 1971.

101. Rubin RA, Balow B: Perinatal influences on the behavior and learning problems of children, in Lahey B, Kazdin A (eds): Advances in Clinical Child Psychology, Vol. 1. New York, Plenum, 1977.

102. Nichols P, Chen T: Minimal Brain Dsyfunction: A Prospective Study. Hillsdale, New Jersey, Erlbaum, 1981.

103. Rapoport JL, Quinn PO, Burg C, Bartley L: Can hyperactives be identified in infancy?, in Trites $R$ (ed): Hyperactivity in Children. Baltimore, University Press, 1979. 
104. Quinn PO, Rapoport JL: Minor physical anomalies and neurologic status in hyperactive boys. Pediatrics 53:742-747, 1974.

105. Halverson CF, Victor JB: Minor physical anomalies and problem behavior in elementary school children. Child Develpm 47:281-285, 1976.

106. Waldrop MF, Bell RQ, McLaughlin B, Halverson CF: Newborn minor physical anomalies predict short attention span, peer aggression, and impulsivity at age 3. Science 199:563-565, 1978.

107. Waldrop M, Pederson F, Bell R: Minor physical anomalies and behavior in preschool children. Child Develpm 39:391-40, 1968.

108. Rapoport J, Quinn P, Lamprecht F: Minor physical anomalies and plasma dopamine- $\beta$-hydroxylase activity in hyperactive boys. Amer J Psychiat 131:386-390, 1974.

109. Morrison J, Stewart M: A family study of the hyperactive child syndrome. Biol Psychiat 3:189-195, 1971.

110. Morrison J, Stewart M: The psychiatric status of the legal families of adopted hyperactive children. Arch Gen Psychiat 28:888-891, 1973.

111. Cantwell DP: Familial-genetic research with hyperactive children, in Cantwell DP (ed): The Hyperactive Child: Diagnosis, Management, Current Research. Hollywood, New York, Spectrum, 1975.

112. Safer D: A familial factor in minimal brain dysfunction. Behav Genetics 3:175-187, 1973.

113. Rieder R, Nichols P: Offspring of schizophrenics III. Arch Gen Psychiat 36:665-674, 1979.

114. Willerman L: Activity level and hyperactivity in twins. Child Develpm 44:228-293, 1973.

115. Deutsch CK, Swanaon JM, Bruell JH, et al: Overrepresentation of adoptees in children with attention deficit disorder. Behav Genetics 12:231, 1982.

116. Ferguson B, Rapoport JL: Nosological issues and biological validation, in Rutter M (ed): Developmental Neuropsychiatry. New York, Guilford, 1983, pp 369-384.

117. Hunt RD, Cohen DJ, Shaywitz SE, Shaywitz BA: Strategies for study of the neurochemistry of attention deficit disorder in children. Schizoph Bull 8:236, 1982.

118. Young JG, Cohen DJ, Shaywitz SE, et al: Assessment of brain function in clinical pediatric research: Behavioral and biological strategies. Schizoph Bull 8:205, 1982.

119. Shaywitz B, Cohen C, Bowers M: CSF monoamine metabolites in children with minimal brain dysfunction-Evidence for alteration of brain dopamine. J Pediat 90:67-71, 1977.

120. Wender P: Minimal Brain Dysfunction in Children. New York, Wiley, 1971.

121. Seiden L, Dykstra L: Psychopharmacology. New York, Van Nostrand Reinhold, 1977.

122. Shaywitz SE, Cohen DJ, Shaywitz BA: The biochemical basis of minimal brain dysfunction. J Pediat 92:179-187, 1978.

123. Wender PH: Minimal brain dysfunction: An overview, in Lipton MA, 
DiMascio A, Killan KF (eds): Psychopharmacology: A Generation of Progress. New York, Raven, 1978.

124. Campbell S: Mother-child interaction: A comparison of hyperactive, learning-disabled, and normal boys. Amer J Orthopsychiat 45:51-57, 1975.

125. Cunningham $C$, Barkley $R$ : The interactions of normal and hyperactive children with their mothers in free play and structural tasks. Child Develpm 50:217-224, 1979.

126. Whalen C, Henker B, Detemote S: Teacher response to the methylphenidate (Ritalin) versus placebo status of hyperactive boys in the classroom. Child Develpm 52:1004-1014, 1981.

127. Loney J, Langhorne J, Paternite C, et al: The Iowa HABIT: Hyperkinetic/ aggressive boys in treatment, in Sells S (ed): Life History Research in Psychopathology, Vol. 6. New York, William \& Wilkins, 1980.

128. Lang AR, Pelham WE, Johnston CJ, Gelerntes S: Effects of deviant child behavior on adult stress and alcohol consumption: A laboratory investigation. Paper presented at the annual meeting of the Southeastern Psychological Association, Atlanta, March 1985. 